\title{
Effects of Royal Jelly on the Prefrontal Cortex in a Rat - Morphine Toxicity Model
}

\author{
Cyrus Jalili', Shiva Roshankhah², Mohammad Mehdi Mohammadi ${ }^{3}$,Mohammad Reza Salahshoor ${ }^{2 *}$ \\ ${ }^{1}$ Medical Biology Research Center, Kermanshah University of Medical Sciences, Kermanshah, Iran \\ ${ }^{2}$ Department of Anatomical Sciences, Medical School, Kermanshah University of Medical Sciences, Kermanshah, Iran \\ ${ }^{3}$ School of Nursing and Midwifery, Kermanshah University of Medical Sciences, Kermanshah, Iran
}

Corresponding Author: Mohammad Reza Salahshoor, PhD, Associate Professor, Department of Anatomical Sciences, Medical School, Kermanshah University of Medical Sciences, Kermanshah, Iran. Tel: +98-9188360349, Email: reza.salahshoor@yahoo.com

Received February 13, 2019; Accepted June 2, 2019; Online Published June 30, 2019

\begin{abstract}
Introduction: Royal jelly (RJ) is a honey bee secretion with numerous medicinal properties and antioxidant activities. Morphine is a major risk factor in the development of functional disorders in several organ systems. This study was designed to evaluate the effects of RJ against morphineinduced damage to the prefrontal cortex of rats.

Materials and Methods: In this study, 48 male Wistar rats were randomly assigned into 6 groups: sham group, morphine group, RJ groups (100, and $200 \mathrm{mg} / \mathrm{kg}$ ), and morphine + RJ groups. Treatments were administered intraperitoneally and orally for 20 days on a daily basis. Ferric reducing/ antioxidant power (FRAP) method was applied to determine the total antioxidant capacity. The number of neurons and, dendritic spines were investigated by Golgi technique, and Griess technique was employed to determine the serum nitrite oxide level.

Results: Morphine administration significantly increased the nitrite oxide level and total antioxidant capacity, and reduced neuronal dendritic spines and neurons compared to the sham group $(P<0.05)$. In all RJ and Morphine + RJ groups, the number of neurons and neuronal dendritic spines were elevated significantly, while nitrite oxide level and total antioxidant capacity were reduced compared to the morphine group $(P<$ 0.05).

Conclusions: RJ administration protected animals against oxidative stress and nitrite oxide. It also improves some prefrontal cortex parameters including number of neurons and dendritic spines because of the morphine.

Keywords: Royal Jelly, Prefrontal Cortex, Morphine

Citation: Jalili C, Roshankhah S, Mohammadi MM, Salahshoor MR. Effects of royal jelly on the prefrontal cortex in a rat - morphine toxicity model. J Appl Biotechnol Rep. 2019;6(2):73-78. doi:10.29252/JABR.06.02.06.
\end{abstract}

\section{Introduction}

Antioxidant compounds can reduce the oxidative stress. ${ }^{1}$ Royal jelly (RJ) is a mixture of different secretions of mandibular glands in honeybees and plays a key role in neonatal growth as well as completion of special sexual features. ${ }^{2}$ Bees feed on RJ in the first three days and their diet is changed afterwards. ${ }^{3} \mathrm{RJ}$ contains a wide range of chemical compounds such as proteins (17\%-45\% dry weight), Jelleines, lipids, fatty acids, carbohydrates, and vitamins. ${ }^{4}$ The antioxidant activity of RJ inhibits oxidative stress and protects DNA against oxidative stress. ${ }^{5}$ Dalfardi et al reported the protective effects of RJ against the toxic effects of silver nanoparticles on the hippocampus of male rats. ${ }^{6}$ Furthermore, Teixeira et al indicated that the administration of RJ improved the brain antioxidant system in rats. ${ }^{7}$ Opioids produce free radicals and cause apoptosis in certain cells. Morphine is an opioid analgesic drug, and the main psychoactive chemical in opium. ${ }^{8}$ It is addictive and causes physiological dependence, which spreads throughout the brain tissues in 10-20 seconds. ${ }^{9,10}$ It then rapidly passes through the blood-brain barrier, and can regulate brain neurotransmitters, including catecholamine and serotonin A. ${ }^{11}$ Meanwhile, dopaminergic structure shows a significant role in controlling the memory. ${ }^{12}$ Morphine acetylcholine receptors are observed in pathways such as accumbens nucleus and ventral tegmental. Stimulation of these receptors increases dopamine release in the prefrontal cortex and induces feelings of euphoria in the user. ${ }^{13}$ However, morphine can induce oxidative stress in organs such as the brain., ${ }^{14}$ increase oxidative stress and neuronal apoptosis, destroy DNA, and produce reactive oxygen species. ${ }^{14-16}$ Among the brain areas heavily affected by morphine is mesocorticolimbic and brain's prefrontal regions. ${ }^{17}$ The prefrontal cortex of the brain has a key role in the state of mind. ${ }^{18}$ The purpose of studying the prefrontal cortex is to specify its function in regulatory performance, judgment, and behavior. ${ }^{19}$ Considering the effects of morphine toxicity on the brain and the therapeutic properties of RJ, the present study was designed and conducted to investigate the effects of RJ on morphine-induced toxicity in the brain's prefrontal region of male rats.

Copyright $\odot 2019$ The Author(s). This is an open-access article distributed under the terms of the Creative Commons Attribution License (http:// creativecommons.org/licenses/by/4.0), which permits unrestricted use, distribution, and reproduction in any medium, provided the original work is properly cited. 


\section{Materials and Methods}

Study Groups and Treatment of Animals

This experimental study was conducted from December 2017 to April 2018 in the Department of Anatomy of a medical school in Kermanshah University of Medical Sciences, Iran. A total of 48 male rats were randomly divided into 6 groups, each including 8 rats. The sham group received normal saline through intraperitoneal injection equivalent to the amount experimental groups received. In the second group, morphine was administered intraperitoneally, injecting $20 \mathrm{mg} / \mathrm{kg}$ once daily in the first 5 days, and twice per day in the following five days. From the eleventh to the twentieth day, a dose of up to 30 $\mathrm{mg} / \mathrm{kg}$ was twice administered on a daily basis. The third and fourth groups were the RJ groups, where each animal, orally (via gavage), received 100 and $200 \mathrm{mg} / \mathrm{kg}$ of RJ once daily, on days 1-20. The sixth to eighth groups were Morphine + RJ groups, were each animal received 100 and $200 \mathrm{mg} / \mathrm{kg}$ of RJ once daily via gavage plus morphine intraperitoneally, on days $1-20.6,7,9$

\section{Animals}

In this experimental study, 48 male Wistar rats (weighing 220-250 g) were purchased from the Pasteur Institute and transferred to the animal house in medical school. During the study, the animals were kept under standard conditions (i.e., $12 \mathrm{~h}$ light $/ 12 \mathrm{~h}$ dark and $22 \pm 2^{\circ} \mathrm{C}$ ), humidity of $50 \%-60 \%$, in special cages and on a straw bed. Water and food were freely available to the animals. Standard food included a plate and treated municipal water to feed the animals. All investigations conformed to the ethical and human principles of research and were approved by the Ethics Committee (ethics certificate No. 97737). ${ }^{1}$

\section{Transcardiac Perfusion}

In this process, the animals were anesthetized with ketamine $(87 \mathrm{mg} / \mathrm{kg})$ and xylazine $(13 \mathrm{mg} / \mathrm{kg})$. The chest was opened and the left ventricle was pierced. A glass cannula was inserted and fixed in the ascending aorta. The left ventricle pathway was cut and the ascending aorta was connected to a plastic tube while the descending aorta was clamped. The cannula was linked to the normal saline. The descending aorta was fastened and, after washing the brain, the solution was removed through the incision made in the right atrium. Formalin 5\% and buffer phosphate 7\% were inoculated into the brain by the cannula, and the brains were fixed in 15 minutes. ${ }^{12}$

\section{Golgi Methods}

Golgi method was used to observe the number of neurons and neuron dendrites in the prefrontal cortex. This method was applied using potassium dichromate followed by silver nitrate. Following brain fixation, tissue blocks were placed inside 3\% potassium dichromate solution for 48 hours in a dark environment. The blocks were washed in $0.75 \%$ silver nitrate solution and were put inside the solution for 72 hours. The tissues were washed in $1 \%$ silver nitrate solution. Thereafter, tissue processing, counting dehydration, clearing, and embedding were performed. Microscopic sections $(5 \mu \mathrm{m})$ were prepared and examined morphologically. ${ }^{13}$

\section{Dendritic Thorns}

Dendritic thorn count was made via microscopic examination with an optical microscope and Motic software and ImageTool IT (version 3) software. In the slides stained through Golgi staining technique, we included neurons entirely stained with cell bodies in the central part of the tissue slices away from the surrounding stained neurons. The dendritic tree of pyramidal neurons was demonstrated through camera Lucida at $750 \times$ magnification, where the dendritic exclusion order from the cell body was used for counting the dendritic pieces. ${ }^{20}$

\section{Griess Technique}

Nitrite oxide was measured by Griess assay using microplate technique. In this process, zinc sulfate powder $(6 \mathrm{mg})$ was mixed with serum samples $(400 \mu \mathrm{L})$, and vortexed for $1 \mathrm{~min}$. The samples were centrifuged at $4^{\circ} \mathrm{C}$ for 10 minutes at 12,000 rpm with supernatant used to measure the nitrite oxide. Briefly, $50 \mu \mathrm{L}$ of the sample was added to $100 \mu \mathrm{L}$ of Griess reagent (Sigma; USA) and the reaction mixture was incubated for about 30 minutes at room temperature. The optical density (OD) of the sample was measured by an ELISA reader (Hyperion; USA) at a wavelength of $540 \mathrm{~nm}$ according to the manufacturer's protocol. ${ }^{1}$

\section{FRAP Method}

Ferric reducing/antioxidant power (FRAP) method was used in order to the measure the total antioxidant capacity of the serum (Abcam, ab234626). Prior to the transcardiac method, venipuncture was done on the animals' hearts (right ventricle) using a $5 \mathrm{cc}$ syringe. The blood sample was incubated for 15 minutes at $37^{\circ} \mathrm{C}$ to clot. The clotted blood was then centrifuged for 15 minutes at $3000 \mathrm{rpm}$ until the serum was separated. The separated serum was stored at $-70^{\circ} \mathrm{C}$ until antioxidant capacity level was measured. In this technique, the ability of the plasma to reinstate ferric ions was measured, a process requiring a high quantity of $\mathrm{Fe}^{\mathrm{III}}$. A blue stain was formed when the compound of Fe ${ }^{\mathrm{III}}$-TPTZ in acidic $\mathrm{pH}$ returned to $\mathrm{Fe}^{\mathrm{II}}$, and was absorbed at a maximum wavelength of $593 \mathrm{~nm}$. The only factor defining the speed of $\mathrm{Fe}^{\mathrm{II}}$-TPTZ and the blue color is the vitalizing power of the sample. Total antioxidant capacity values were strategized via the standard curve with diverse concentrations of iron sulfate. ${ }^{1}$

\section{Statistical Analysis}

The one-way analysis of variance (ANOVA) was used for statistical analysis and Tukey post hoc test was employed to determine the difference between the groups. SPSS 16 was used for data analysis. The obtained results were expressed as mean \pm standard error and $P<0.05$ was considered as statistically significant.

\section{Results}

Number of Neurons

A significant decline was observed in the number of neurons in the brain prefrontal cortex in the morphine group compared to the sham group $(P<0.05)$. The mean number 
of neurons was not significant in either RJ groups compared to the sham group $(P>0.05)$. Further, the mean of pyramidal neurons increased significantly in RJ and morphine + RJ groups compared to the morphine group $(P<0.05$, Figure 1 and Table 1).

Number of Dendritic Processes

The results of the number of dendritic processes in the prefrontal cortex revealed a significant reduction in the morphine group compared to the sham group $(P<0.05)$. The mean number of dendritic processes was not significant in either RJ groups compared to the sham group $(P>0.05)$. Also, the mean of dendritic processes increased significantly in both RJ and Morphine + RJ groups compared to the
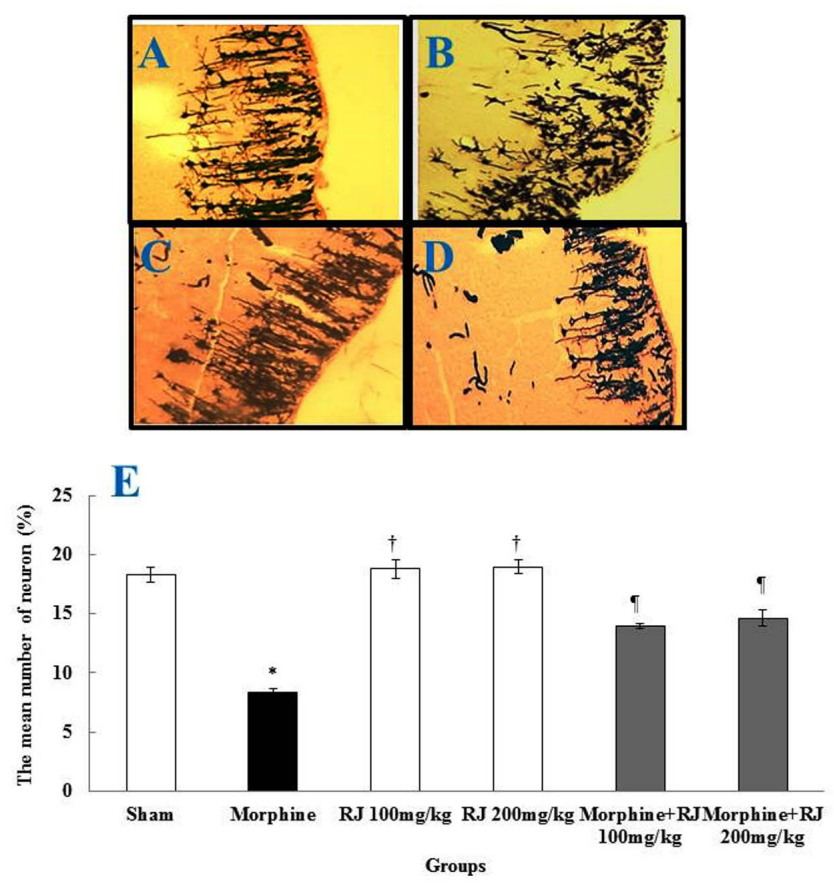

Figure 1. Effect of Morphine and RJ Administration on the Mean Number of Neurons. A-D: $5 \mu \mathrm{m}$ thick sections, Golgi staining, at $\times 100$ magnification; Prefrontal cortex section in the sham group (A), the normal number of neurons; morphine group (B), reduced neurons cells; RJ (200 mg/ $\mathrm{kg}$ ) group (C), a normal number of neurons; Morphine $+\mathrm{RJ}(200 \mathrm{mg} / \mathrm{kg})$ a normal number of neurons. E: *Significant difference compared to the sham group $(P<0.05)$. ${ }^{+}$Significant difference compared to the morphine group $(P<0.05)$. "Significant difference compared to the morphine group $(P<0.05)$. morphine group $(P<0.05$, Figure 2 and Table 1$)$.

\section{Dendritic Spines}

The average percentage of neuronal dendritic spines in experimental groups presented a significant fall between the sham group and morphine group $(P<0.05)$. Note that, the average percentage of neuronal dendritic spines was not significant in either RJ groups compared to the sham group $(P$ $>0.05)$. Furthermore, in both RJ and morphine + RJ groups, the average percentage of neuronal dendritic spines rose significantly in all treated rats compared with the morphine group $(P<0.05$, Figure 3 and Table 1$)$.

\section{Nitrite Oxide}

The results of blood serum nitrite oxide measurement revealed a significant growth in morphine group compared

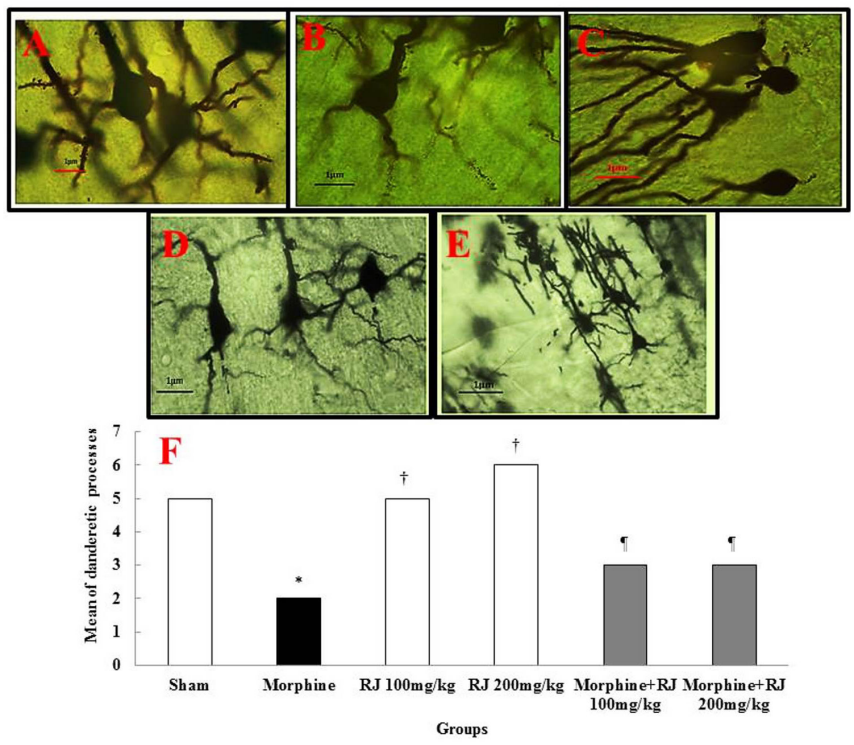

Figure 2. Comparison of Morphine, RJ, and Morphine + RJ Groups Concerning the Mean Number of Dendritic Prosesses in the Prefrontal Cortex. A-E: Fivemicron thick sections, Golgi staining, magnification $\times 100$. Prefrontal section in the sham group (A), normal structure; Morphine groups (B and C), reduced number of dendritic prosesses; RJ (200 mg/kg) group (D), normal structure. Morphine + RJ (200 mg/kg) (D), normal structure; F: " Significant difference compared to the sham group $(P<0.05) .{ }^{+}$Significant difference compared to the Morphine group $(P<0.05)$. "Significant difference compared to the morphine group $(P<0.05)$

Table 1. Effect of Morphine, RJ and RJ + Morphine on Prefrontal Cortex Parameters in Male Rats

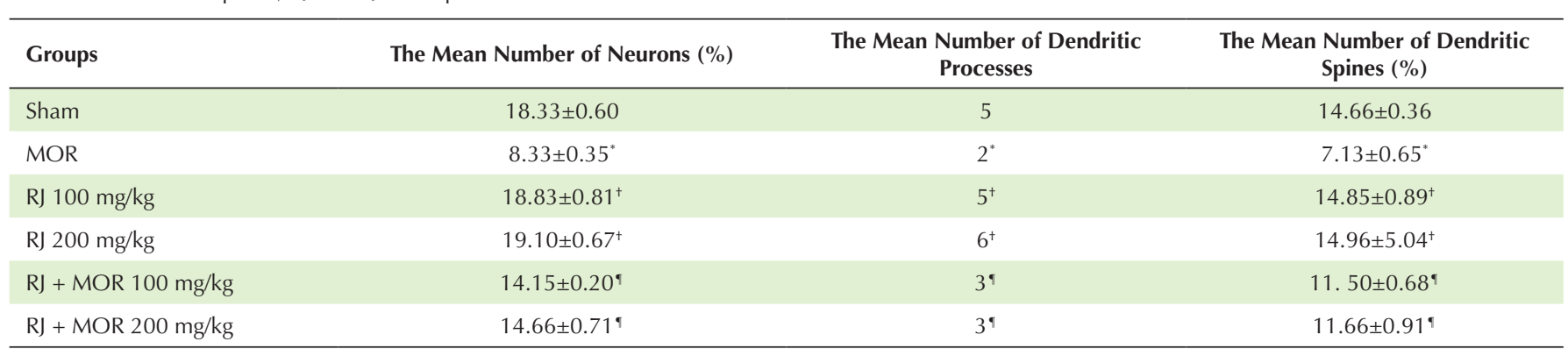

Data are presented as mean $\pm \mathrm{SD} .{ }^{*} P<0.01$ compared to the Sham group. $+P<0.05$ compared to MOR group. $\boldsymbol{I} P<0.05$ compared to the MOR group. RJ, Royal jelly; MOR: Morphine. 

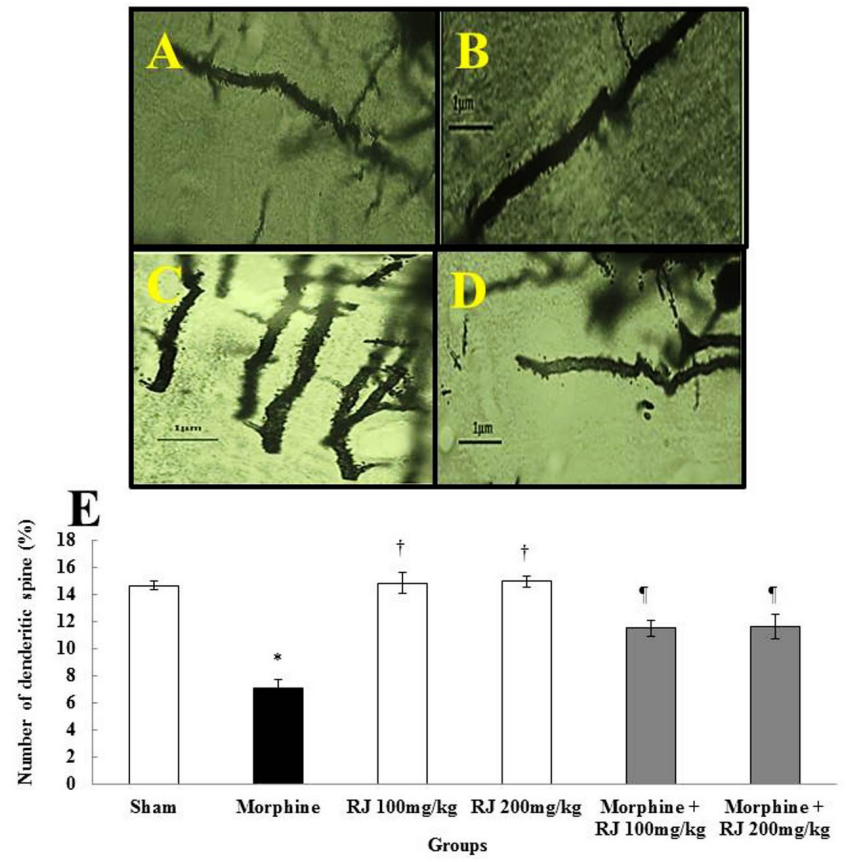

Figure 3. Comparison of Morphine, RJ, and Morphine + RJ Groups Regarding the Mean Number of Dendritic Spines in the Prefrontal Cortex; A-D: Five-micron thick sections, Golgi staining, magnification $\times 100$. Sham group (A), normal structure; Morphine group (B), reduced number of dendritic spines; RJ (200 mg/kg) group (C), normal structure; Morphine + RJ $(200 \mathrm{mg} / \mathrm{kg})(\mathrm{D})$, normal structure. E: *Significant difference compared to the sham group $(P<0.05)$. Hignificant difference with the morphine group $(P<0.05)$. Significant difference compared to the morphine group $(P<0.05)$.

to the sham group $(P<0.05)$. The mean nitrite oxide in the blood serum was not significant in either RJ groups compared to the sham group $(P>0.05)$. On the other hand, the mean nitrite oxide levels in the blood serum declined significantly in RJ and Morphine + RJ groups in both doses compared to the morphine group $(P<0.05$, Figure 4 and Table 2$)$.

\section{Total Antioxidant Capacity}

The results showed that the total antioxidant capacity serum level dropped significantly in the morphine group compared to the sham group $(P<0.05)$. The total antioxidant capacity level was significantly enhanced in both RJ and Morphine + RJ groups compared to the morphine group $(P<0.05$, Figure 5 and Table 2).

\section{Discussion}

The prefrontal cortex plays an important role in growth and development. ${ }^{21}$ Morphine entails many implications and side effects by influencing the central nervous system. ${ }^{22}$ Based on the results of this study, it can be generally argued that morphine has detrimental effects on the prefrontal cortex. Further, the number of neurons, dendritic processes, and dendritic thorns was significantly reduced in the morphine group in comparison to the sham group. In RJ and morphine + RJ groups, there was a significant increase in the number of dendritic processes and thorns compared to the morphine group. The results may indicate the RJ-induced neurodegeneration. ${ }^{23}$ In line with the present research, Mulder
Table 2. Effect of Morphine, RJ and RJ + Morphine on Nitrite Oxide and Total Antioxidant Capacity in Rats

\begin{tabular}{lcc}
\hline Groups & $\begin{array}{c}\text { The Mean of Nitrite } \\
\text { Oxide Level }(\%)\end{array}$ & $\begin{array}{c}\text { The Mean of TAC } \\
(\mathbf{m m o l} / \mathrm{L})\end{array}$ \\
\hline Sham & $26.72 \pm 1.46$ & $1.99 \pm 0.03$ \\
\hline MOR & $50 \pm 2.09^{*}$ & $0.58 \pm 0.11^{*}$ \\
RJ $100 \mathrm{mg} / \mathrm{kg}$ & $24.66 \pm 1.11^{+}$ & $2.09 \pm 0.04^{+}$ \\
RJ $200 \mathrm{mg} / \mathrm{kg}$ & $25.37 \pm 3.09^{+}$ & $2.03 \pm 0.10^{+}$ \\
RJ + MOR $100 \mathrm{mg} / \mathrm{kg}$ & $28.92 \pm 3.12^{\uparrow}$ & $1.24 \pm 0.04^{\uparrow}$ \\
\hline RJ + MOR $200 \mathrm{mg} / \mathrm{kg}$ & $25.74 \pm 3.10^{\uparrow}$ & $1.28 \pm 0.12^{\uparrow}$ \\
\hline
\end{tabular}

RJ: royal jelly, MOR: morphine,TAC: total antioxidant capacity.

Data are presented as mean \pm SD. ${ }^{*} P<0.01$ compared to the Sham group. ${ }^{+} P<$ 0.05 compared to MOR group. ${ }^{\natural} P<0.05$ compared to the MOR group.

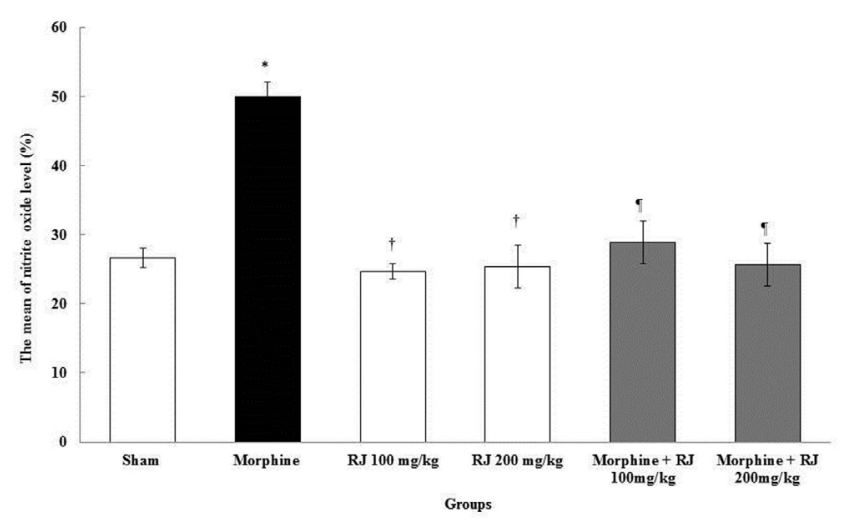

Figure 4. Effects of RJ, Morphine, and Morphine + RJ on the Mean Nitrite Oxide Level. *Significant difference compared to the sham group $(P<0.05)$. +Significant difference compared to the morphine group $(P<0.05)$. I Significant difference compared to the morphine group $(P<0.05)$.

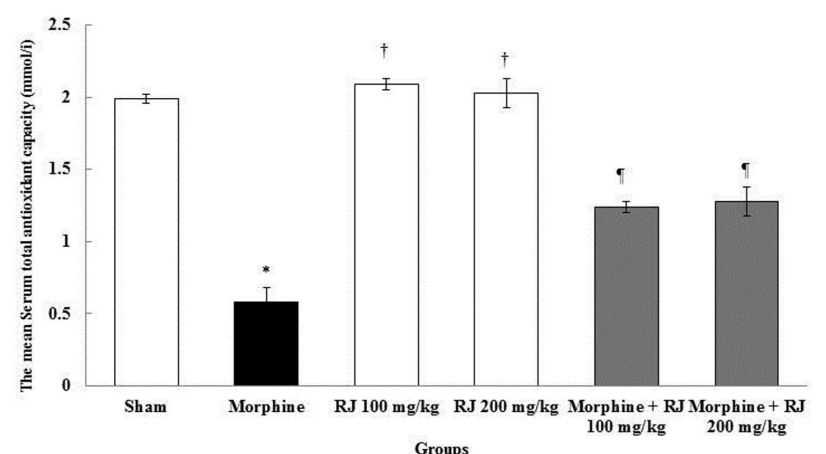

Figure 5. Comparison of the Mean Total Antioxidant Capacity in Morphine, RJ, and Morphine + RJ groups. *Significant difference compared to the sham group $(P<0.05)$. HSignificant difference compared to the morphine group $(P<0.05)$. $\neq$ Significant difference compared to the morphine group $(P<0.05)$.

et al found that morphine was able to damage the cells in the brain cortex via increased protein accumulation. ${ }^{24}$ It seems that morphine induces oxidative stress, thereby producing free radicals which cause cell damage. ${ }^{9}$ The free radicals generated following oxidative stress may have the potential to damage cellular compositions, including proteins, lipids, and DNA. ${ }^{1}$ The lipid in the membrane of the nerve cells has a 
high content of oxidized unsaturated fatty acids. Therefore, it seems that morphine can produce reactive oxygen species via $\mathrm{P}-450$ enzyme and damage the nucleus in the neurons. ${ }^{25}$ Many brain diseases are associated with changes in the morphology and density of dendritic thorns. ${ }^{13}$ Morphine can reduce the length and number of dendritic thorns in nucleus accumbens by affecting the neurotropic factors in the striatum. ${ }^{26} \mathrm{~A}$ study by Robinson et al revealed that morphine injections reduced the length and the number of dendritic thorns, which is consistent with the results of our study. ${ }^{27}$ It seems that morphine can destroy dendritic thorns by $\beta 2$-nAChRs deactivation at postsynaptic cells in prefrontal cortex. ${ }^{28}$ It can further reduce the number of thorns by deactivating $\alpha 4 \beta 2$ nAChRs in the pre-synaptic membrane. ${ }^{29} \mathrm{RJ}$ is a purifier of reactive oxygen species and has the potential to destroy oxidative stress. ${ }^{30}$ Corroborating the results of the present study, Araki et al reported that RJ has protective effects against Tyrosine Kinase Inhibitor-induced toxicity in patients with renal cell carcinoma. ${ }^{31} \mathrm{RJ}$ can control the production of cyanide-induced superoxide. ${ }^{32}$ Jalili et al found that aqueous extract of Boswellia serrata administration as an antioxidant caused increased number of dendritic processes and thorns in kindled rats, confirming the results of the present study. ${ }^{13}$ It also amplified the effects of antioxidant enzymes such as catalase and superoxide dismutase, and reduced ROS production. ${ }^{33}$ In the current study, a significant growth was observed in serum nitrite oxide and serum total antioxidant levels in the morphine group compared to the sham group. In RJ and morphine + RJ groups, there was a significant drop in serum nitrite oxide and serum total antioxidant levels in comparison to the morphine group. The results of Jalili et al confirmed the results of the current study, demonstrating that the prescription of pentoxifylline as an strong antioxidant decrease nitrite oxide level in rats treated by Nitrosamine. ${ }^{1}$ Nitrite oxide is a free radical which can regulate angiogenesis, apoptosis and cell cycle. ${ }^{1}$ Morphine can stimulate nitrite oxide receptors in the brain and increase glutamate release and NMDA activation. The activation of NMDA may increase the formation of nitrite oxide in the prefrontal cortex. ${ }^{34}$ The results of a study by Keser et al suggested that exposure to morphine increased the activity of nitrite oxide in the frontal cortex, which is consistent with the results of the present study. ${ }^{35}$ The reduction in total antioxidant capacity level in this study indicates the effects of the oxidative stress induced by morphine on the prefrontal neurons. Morphine induces oxidative stress in neural tissue, which is represented bya growth in the levels of ROS and a reduction in the activity of antioxidant enzymes such as total antioxidant capacity. ${ }^{36}$ Jalili et al reported that the administration of Resveratrol as an antioxidant decreased total antioxidant capacity in rats treated with Malathion, which is in line with the findings of the present study. ${ }^{37}$ In the present study, the improved levels of total antioxidant capacity in rats treated with RJ highlight the antioxidant effects of RJ. ${ }^{6}$ The high antioxidant level rise due to the administration of morphine indicates the positive impact of RJ on magnified antioxidant effects. It is further assumed that RJ inhibits the synthesis of nitrite oxide induction enzyme. ${ }^{38}$ In line with the present research, Sugiyama et al reported RJ administration to inhibit nitrite oxide production. ${ }^{39}$ The results of the present study suggested that RJ administration in both studied doses might have a positive effect on morphine-induced toxicity, as an oxidative stress, in the neurons of the prefrontal cortex; these effects are not dose-dependent concerning RJ.

\section{Conclusions}

It appears that $\mathrm{RJ}$ provides protection against oxidative stress, resulting from the morphine in the prefrontal cortex. Such ability of RJ might be due to its strong potential antioxidant attributes. RJ administration moderates the antioxidant agents, resulting in prefrontal cortex recovery and prevention of morphine adverse effects on the total antioxidant capacity, nitrite oxide, number of neurons, and dendritic spines as evidenced in the male rats.

\section{Authors' Contributions}

MRS and CJ carried out the experiments, analyzed and interpreted the data, and drafted the manuscript. MMM and SR designed the study and participated in analysis and interpretation of data. MRS coordinated the study, revised the manuscript and approved the final version to be submitted for publication and helped in the analysis and interpretation of data. All authors read and approved the final manuscript.

\section{Conflict of Interest Disclosures}

The authors declare they have no conflicts of interest.

\section{Acknowledgments}

We gratefully acknowledge the Research Council of Kermanshah University of Medical Sciences (no: 97737) for the financial support.

\section{References}

1. Jalili C, Moradi D, Roshankhah S, Salahshoor MR. Effect of pentoxifylline on kidney damage induced by nitrosamine in male rats. Res Pharm Sci. 2019;14(1):64-73. doi:10.4103/17355362.251854 .

2. Kanbur M, Eraslan G, Beyaz L, et al. The effects of royal jelly on liver damage induced by paracetamol in mice. Exp Toxicol Pathol. 2009;61(2):123-132. doi:10.1016/j.etp.2008.06.003.

3. Hossen MS, Nahar T, Gan SH, Khalil M. Bioinformatics and therapeutic insights on proteins in royal jelly. Curr Proteomics. 2019;16(2):84-101. doi:10.2174/157016461566618101211313 0 .

4. Viuda-Martos M, Ruiz-Navajas Y, Fernández-López J, PérezÁlvarez JA. Functional properties of honey, propolis, and royal jelly. J Food Sci. 2008;73(9):R117-24. doi:10.1111/j.17503841.2008.00966.x.

5. Maqsoudlou A, Mahoonak AS, Mora L, Mohebodini H, Toldrá F, Ghorbani M. Peptide identification in alcalase hydrolysated pollen and comparison of its bioactivity with royal jelly. Food Res Int. 2019;116:905-915. doi:10.1016/j.foodres.2018.09.027.

6. Dalfardi M, Taghavi MM, Shariati Kohbanani M, et al. Protective and modulatory effects of royal jelly used against the induced changes in silver nanoparticles on the Hippocampus of male rats. Nanomed J.2019;6(2):136-141.doi:10.22038/NMJ.2019.06.0008.

7. Teixeira RR, de Souza AV, Peixoto LG, et al. Royal jelly decreases corticosterone levels and improves the brain antioxidant system in restraint and cold stressed rats. Neurosci Lett. 2017;655:179-185. doi:10.1016/j.neulet.2017.07.010.

8. Grace PM, Galer EL, Strand KA, Corrigan K, Berkelhammer D, Maier SF, et al. Repeated morphine prolongs postoperative pain in male rats. Anesth Analg. 2019;128(1):161-167. doi:10.1213/ ANE.0000000000003345. 
9. Salahshoor MR, Khashiadeh M, Roshankhah Sh, Kakaberaei S, Jalili C. Protective effect of crocin on liver toxicity induced by morphine. Res Pharm Sci. 2016;11(2):120-129. doi:10.1016/j. neulet.2017.07.010.

10. Ruan H, Sun J, Liu X, Liu L, Cui R, Li X. Cholinergic M4 receptors are involved in morphine-induced expression of behavioral sensitization by regulating dopamine function in the nucleus accumbens of rats. Behav Brain Res. 2019;360:128-133. doi:10.1016/j.bbr.2018.12.009.

11. Feng J, Lepetre-Mouelhi S, Gautier A, et al. A new painkiller nanomedicine to bypass the blood-brain barrier and the use of morphine. Sci Adv. 2019;5(2):eaau5148. doi:10.1126/sciadv. aau5148.

12. Jalili C, Salahshoor MR, Khademi F, Jalili P, Roshankhah SH. Morphometrical analysis of the effect of morphine administration on brain's prefrontal region in male rat. Int J Morphol. 2014;32(3):761-766. doi:10.4067/S0717-95022014000300003.

13. Jalili C, Pourmotabbed A, Moradi S, Salahshoor MR, Motaghi M. The therapeutic effect of the aqueous extract of Boswellia serrata on the learning deficit in kindled Rats. Int J Prev Med. 2014;5(5):563568. doi:10.1016/j.bbr.2018.12.009.

14. Hamdy MM, Elbadr MM, Barakat A. Bupropion attenuates morphine tolerance and dependence: possible role of glutamate, norepinephrine, inflammation, and oxidative stress. Pharmacol Rep. 2018;70(5):955-962. doi:10.1016/j.pharep.2018.04.003.

15. Arabian M, Aboutaleb N, Soleimani M, Ajami M, Habibey R, Pazoki-Toroudi $\mathrm{H}$. Activation of mitochondrial KATP channels mediates neuroprotection induced by chronic morphine preconditioning in hippocampal CA-1 neurons following cerebral ischemia. Adv Med Sci. 2018;63(2):213-219. doi:10.1016/j. advms.2017.11.003.

16. Iranpour M, Torkzadeh-Tabrizi S, Khatoon-Asadi Z, MalekpourAfshar R. Immunohistochemical Assessment of Inflammation and Regeneration in Morphine-Dependent Rat Brain. Addict Health. 2019;29:156-161. doi:10.22122/ahj.v10i3.651.

17. Ramshini E, Reisi P, Afrozi H, Alaei S, Alehashem M, Eftekharvaghefi S. Effect of intracerebroventricular injection of GABA receptors antagonists on morphine-induced changes in GABA and GLU transmission within the mPFC: an in vivo microdialysis study. Iran J Basic Med Sci. 2019;22(3):246-250. doi:10.22038/ ijbms.2019.28478.6925.

18. Zibman S, Daniel E, Alyagon U, Etkin A, Zangen A. Interhemispheric cortico-cortical paired associative stimulation of the prefrontal cortex jointly modulates frontal asymmetry and emotional reactivity. Brain Stimul. 2019;12(1):139-147. doi:10.1016/j. brs.2018.10.008.

19. Donahue CJ, Glasser MF, Preuss TM, Rilling JK, Van Essen DC. Reply to Barton and Montgomery: a case for preferential prefrontal cortical expansion. Proc Natl Acad Sci. 2019;116(1):56. doi:10.1073/pnas.1819241116.

20. Jalili C, Salahshoor MR, Pourmotabbed A, Moradi S, Motaghi M, Shabanizadeh Darehdori A, et al. The effects of aqueous extract of Boswellia serrata on hippocampal region CA1 and learning deficit in kindled Rats. Res Pharm Sci. 2014;9(5):351-358. doi:10.22038/ ijbms.2019.28478.6925.

21. Huhn AS, Sweeney MM, Brooner RK, et al. Prefrontal cortex response to drug cues, craving, and current depressive symptoms are associated with treatment outcomes in methadone-maintained patients. Neuropsychopharmacol 2019;44(4):826. doi:10.1038/ s41386-018-0252-0.

22. Rowsell L, Wong KK, Yee BJ, et al. The effect of acute morphine on obstructive sleep apnoea: a randomised double-blind placebo-controlled crossover trial. Thorax. 2019;74(2):177-184. doi:10.1136/thoraxjnl-2018-211675.

23. Zamani Z, Reisi P, Alaei H, Pilehvarian AA. Effect of royal jelly on spatial learning and memory in rat model of streptozotocininduced sporadic Alzheimer's disease. Adv Biomed Res. 2012;1:26-30. doi:10.4103/2277-9175.98150.
24. Mulder AH, Hogenboom F, Wardeh G, Schoffelmeer AN. Morphine and Enkephalins Potently Inhibit [3H] Noradrenaline Release from Rat Brain Cortex Synaptosomes: Further Evidence for a Presynaptic Localization of $\mu$-Opioid Receptors. J neurochem. 1987;48(4):1043-7. doi:10.1111/j.1471-4159.1987.tb05624.x

25. Skrabalova J, Karlovska I, Hejnova L, Novotny J. Protective effect of morphine against the oxidant-induced injury in $\mathrm{H} 9 \mathrm{c} 2$ cells. Cardiovasc Toxicol. 2018;18(4):374-85. doi:10.1007/s12012-0189448-0.

26. RobinsonTE, Gorny G, SavageVR, Kolb B. Widespread but regionally specific effects of experimenter-versus self-administered morphine on dendritic spines in the nucleus accumbens, hippocampus, and neocortex of adult rats. Synapse. 2002;46(4):271-279. doi:10.1002/ (SICI)1098-2396(199908)33:2<160::AID-SYN6>3.0.CO;2-S.

27. Robinson TE, Kolb B. Morphine alters the structure of neurons in the nucleus accumbens and neocortex of rats. Synapse. 1999;33(2):160-162. doi:10.1002/(SICI)10982396(199908)33:2<160::AID-SYN6>3.0.CO;2-S.

28. Samochocki M, Zerlin M, Jostock R, Groot Kormelink PJ, Luyten $\mathrm{WH}$, Albuquerque EX, Maelicke A. Galantamine is an allosterically potentiating ligand of the human $\alpha 4 / \beta 2$ nAChR. Acta Neurol Scand. 2000;102:68-73. doi:10.1073/pnas.1819241116.

29. Zheng H, Zeng Y, Chu J, Kam AY, Loh HH, Law PY. Modulations of NeuroD activity contribute to the differential effects of morphine and fentanyl on dendritic spine stability. J Neurosci. 2010;30(24):81028110.doi:10.1523/JNEUROSCI.6069-09.2010.

30. Asadi N, Kheradmand A, Gholami M, Saidi SH, Mirhadi SA. Effect of royal jelly on testicular antioxidant enzymes activity, MDA level and spermatogenesis in rat experimental Varicocele model. Tissue Cell. 2019;57:70-77. doi:10.1016/j.tice.2019.02.007.

31. Araki K, Miyata Y, Ohba K, et al. Oral intake of royal jelly has protective effects against tyrosine kinase inhibitor-induced toxicity in patients with renal cell carcinoma: a randomized, double-blinded, placebo-controlled trial. Medicines. 2019;6(1):2 . doi:10.3390/medicines6010002.

32. Kocot J, Kiełczykowska M, Luchowska-Kocot D, Kurzepa J, Musik I. Antioxidant potential of propolis, bee pollen, and royal jelly: Possible medical application. Oxid Med Cell Longev. 2018;2018:7074209. doi:10.1155/2018/7074209.

33. Nagai T, Inoue R, Suzuki N, Nagashima T. Antioxidant properties of enzymatic hydrolysates from royal jelly. J Med Food. 2006;9(3):363-367. doi:10.1089/jmf.2006.9.363.

34. Mansouri MT, Naghizadeh B, Ghorbanzadeh B, et al. Venlafaxine prevents morphine antinociceptive tolerance: the role of neuroinflammation and the I-arginine-nitric oxide pathway. Exp Neurol. 2018;303:134-141. doi:10.1016/j. expneurol.2018.02.009.

35. Keser A, Nesil T, Kanit L, Pogun S. Brain nitric oxide metabolites in rats preselected for Morphine preference and intake. Neurosci Lett. 2013;545:102-106. doi:10.1016/j.neulet.2013.04.027.

36. Jokinen $V$, Sidorova $Y$, Viisanen $H$, et al. Differential Spinal and supraspinal activation of glia in a rat model of morphine tolerance. Neurosci. 2018;375:10-24. doi:10.1016/j. neuroscience.2018.01.048.

37. Jalili C, Roshankhah S, Moradi Y, Salahshoor MR. Resveratrol attenuates malathion-induced renal damage by declining oxidative stress in rats. Int J Pharma Investig. 2018;8:192-199. doi:10.4103/ jphi.JPHI_7_19.

38. Momeni A, Salahshoor MR, Jalili F, Jalili C. Investigation of the effect of royal jelly on amount of nitric oxide in ovariectomized rats. Pharmacophore. 2017;8(6S):e-1173235. doi:10.1016/j. expneurol.2018.02.009.

39. Sugiyama T, Takahashi K, Kuzumaki A, Tokoro S, Neri P, Mori H. Inhibitory mechanism of 10-hydroxy-trans-2-decenoic acid (royal jelly acid) against lipopolysaccharide-and interferon- $\beta$-induced nitric oxide production. Inflam. 2013;36(2):372-378. doi:10.1007/ s10753-012-9556-0. 